\title{
Assessment of clinical parameters and patient satisfaction submitted to rehabilitation with total joint prostheses of temporomandibular joint
}

Thaiz Carrera Arrabal Fernandes ${ }^{*}$, Luiz Fernando Lobo Leandro², Daniel Emilio González Atencio ${ }^{3}$, Juliana Cama Ranacciato ${ }^{4}$, Rogério Motta $^{5}$, Pietry Dy Tarso Inã Alves Malaquias ${ }^{6}$ and Henry Arturo Garcia Guevara ${ }^{7}$

${ }^{1}$ Department of Oral \& Maxillofacial Surgery of São Leopoldo Mandic Faculty, Campinas and Private Practice, Brazil

${ }^{2}$ Residency of Oral \& Maxillofacial Surgery, Santa Paula Hospital, Brazil.

${ }^{3}$ Department of Oral and Maxillofacial Surgery, Santa Paula Hospital, Brazil.

${ }^{4}$ Department of Pharmacology and Anesthesiology and Medical Therapy of São Leopoldo Mandic Faculty, Campinas, Brazil.

${ }^{5}$ Department of Pharmacology and Anesthesiology and Medical Therapy of São Leopoldo Mandic Faculty, Campinas, Brazil.

${ }^{6}$ Oral \& Maxillofacial Surgeon, Private Practice, Vitória, Brazil.

${ }^{7}$ Research Committee at the OMS Department of the Santa Paula Hospital, Faculty at Santa Maria University, Venezuela.

\begin{abstract}
The aim of this study was to investigate the clinical efficacy of temporomandibular alloplastic prosthesis for full reconstruction of the temporomandibular joint. The total sample was 44 patients, including 17 men and 27 women. Clinical parameters such as deviation and limitation of mouth opening and facial asymmetry, and subjective criteria such as headache, difficulty chewing, local pain and the degree of patient satisfaction postoperatively were used. The mean of the follow up was approximately 5 years. It was observed that the mouth opening postoperatively was higher than that of preoperative showing an average increase of $14.6 \pm 8.04$ mm. Similarly, the measure of laterality and protrusion also increased significantly postoperatively. Reports of snap, crackle, headache, facial asymmetry and mainly local pain significantly decreased (Fisher exact test, $\mathrm{p}<0.05)$ after surgery. It was observed that $33(75 \%)$ subjects had improvement in both chewing and socializing, and $37(84.1 \%)$ showed improvement in chewing and 40 (90.9\%) showed improvement in social life. The results of this research showed that studied the prosthesis is an effective and predictable option for full reconstruction of the TMJ.
\end{abstract}

\section{Introduction}

The Temporomandibular Articulation (TMJ) may be affected by various types of pathologies that can be congenital, acquired (due to trauma), local and systemic, which may lead to sever loss of its structure, morphology and function[1].

Nowadays, thanks to the evolution of alloplastic materials, the TMJ treatment with prosthesis meets the biomechanical and biocompatibility requirements, which makes it reliable with safe results, and so becoming an alternative to autogenous bone grafts. It also shows considerable reduction of surgical time (for not being necessary a donor site), less time of hospitalization and faster recovery of function with no need of maxillo-mandibular fixation during the post-op. On the other hand, disadvantages were found: limited prosthesis size, loss of translation movement causing loss of lateralization e protrusion due to the detachment of lateral pterygoid [2].

The physiological reconstruction of the TMJ represents a big challenge to the Oral and Maxillofacial surgeon when it comes to rheumatoid arthritis, fibrous and bony ankylosis, comminuted condyle fractures and tumors or congenital pathologies, for the objective is to achieve adequate articular function, significant interincisal opening and pain relief [3]. Many prosthesis have been used throughout the years like Biomet/Lorenz, TMJ Implants and TMJ Concepts customized prosthesis using CAD/CAM technology.
This work intended to clinically evaluate patients treated with total TMJ reconstruction, analyzing clinical parameters such as mouth opening amplitude, lateralization, protrusion, facial asymmetry and mouth opening deviation. Furthermore, subjective criteria such as cephalea, masticatory difficulty, local pain and post-op satisfaction level were evaluated [4].

\section{Materials and methods}

In the present study, 44 patients went through clinical and imagenological evaluation, being 17 males and 27 females, with a good health condition, who underwent TMJ prosthesis surgical procedure with a minimum of 12 months post-op, unilateral or bilateral. All the procedures were performed by the same surgeon.

Correspondence to: Thaiz Carrera Arrabal Fernandes, Department of Oral \& Maxillofacial Surgery of São Leopoldo Mandic Faculty, Campinas and Private Practice, Brazil, E-mail: thaizarrabal@gmail.com

Key words: total joint replacement, temporomandibular disorders, TMJ reconstruction, alloplastic reconstruction

Received: November 10, 2017; Accepted: December 20, 2017; Published: December 23, 2017 
In these patients, total substitution of the TMJ was carried out, using Biomet/Lorenz (Biomet Microfixation Jacksonville, Fl, USA) TMJ prosthesis, following the clinical parameters previously described and using the same $200 \mathrm{~mm}$ caliper rule (digimesse brand) as well as a questionnaire to determine the subjective parameters formerly mentioned, from October 2010 to September 2011.

For the prosthesis placement, surgical protocol was followed (Figures 1 to 10). After general anesthesia under naso-traqueal intubation, local anesthetic with vasoconstrictor was infiltrated in preauricular region. Pre-auricular incision and submandibular incision (Risdon approach) are performed. Osteotomy for removal of the ankylosed part is carried out, as well as regularization of the superior wall of the articular cavity, using surgical burs in order to adapt the template. This template is then fixated to the articular fossa/eminence with titanium screws, corroborating the stability and parallelism to the zigomatic arch. Intraoperative maxillo-mandibular fixation was

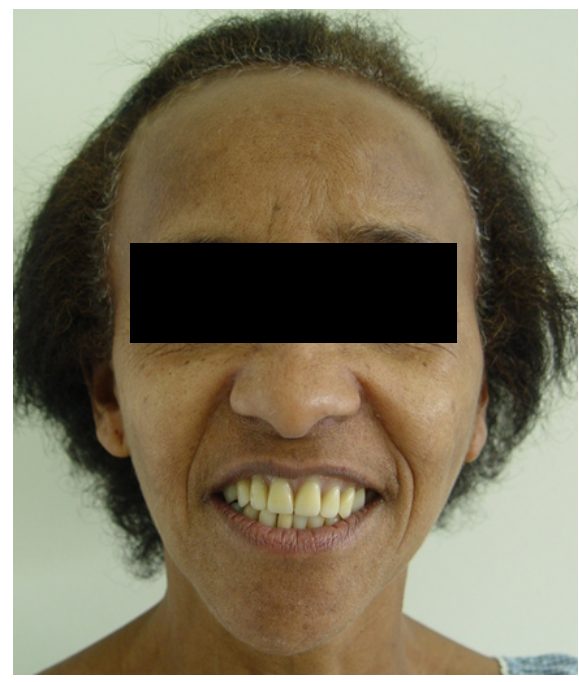

Figure 1. Extra-oral frontal view

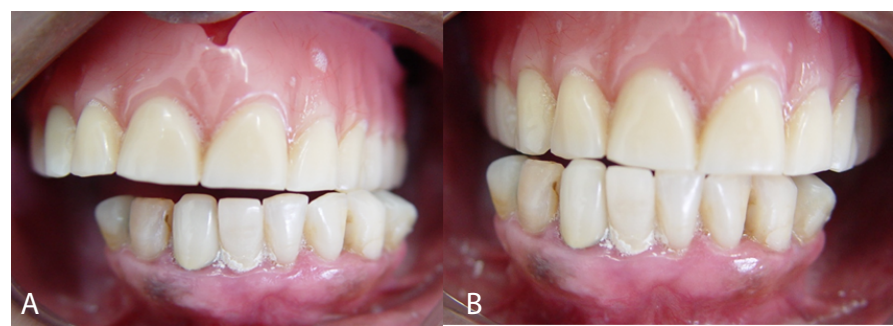

Figure 2. Intra-oral view. Laterality movement.

*A) Left B) Right

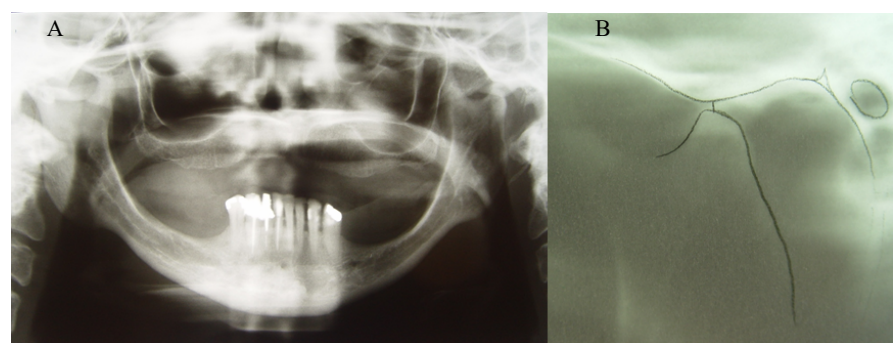

Figure 3. Imaging Exams

A) Panoramic X-ray B) TMJ lateral X-ray . Observe the alteration of the morphology of the condylar head, suggesting degenerative changes.

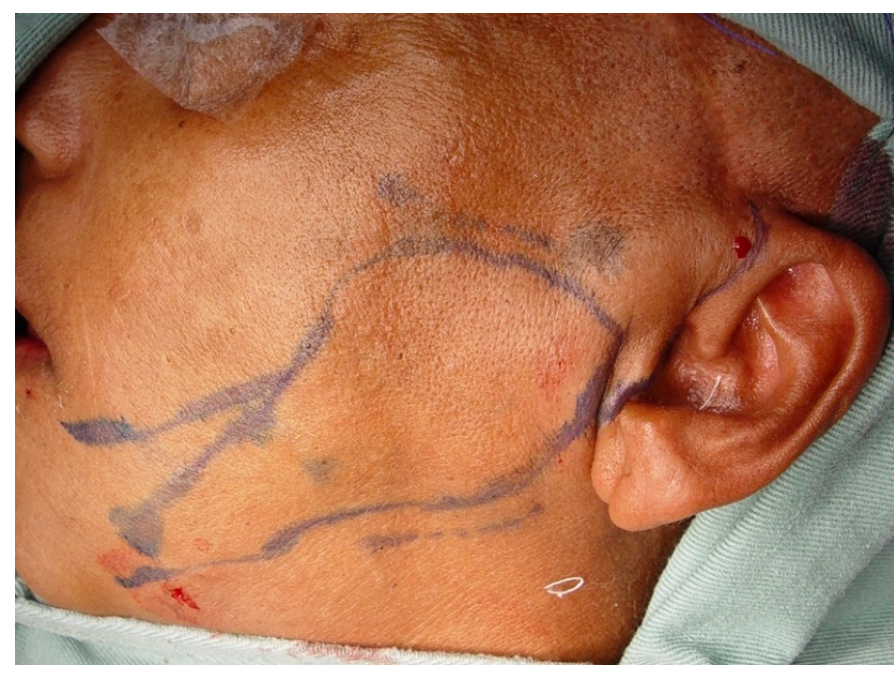

Figure 4. Demarcation of anatomical structures for surgical approach.

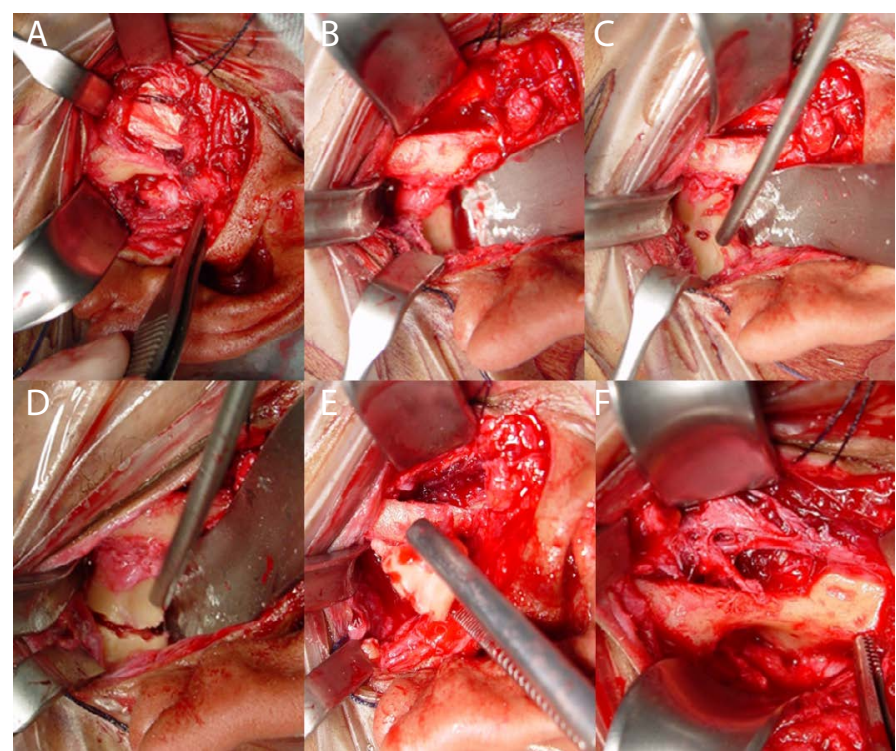

Figure 5. Step-by-step

A and B) access to the condyle region by preauricular incision C, D and E) Osteotomy demarcation and condylar removal F) Bed prepared to receive the joint fossa component

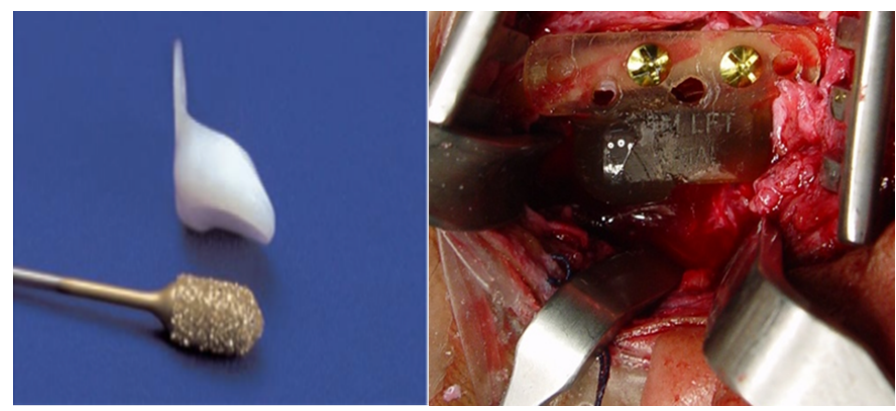

Figure 6. Template adaptation of the articular fossa componente

made in all the patients in order to guarantee occlusal stability. In some patients, who showed limited mobility, coronoidectomy procedure was also performed in order to remove the interference that causes such limitation. All the patients went through physiotherapy with isometric exercises and rehabilitation. 
All the patients had standard criteria of clinical-functional evaluation (Annex A) in which dental general condition, clicking frequency, crepitation, cephalea, facial asymmetry, mouth opening deviation, lateralization and protrusion were searched for. Moreover, post-surgical satisfaction level of the patient was obtained through the questionnaire (Annex B) with five questions personally delivered to the patient, establishing a real analysis about the knowledge regarding to the surgery and its post-op (by the patient) [5].

Analysis of the age factor using the Mann-Whitney test was performed, whereas Wilcoxon test was used to analyze dental general condition and etiologies, clicking frequency, crepitation, cephalea, facial asymmetry, edema, excursion limitation, mouth opening deviation, masticatory difficulty and local pain. Kruskal-Wallis test, was used to evaluate post-op discomfort level, considering opening degree, lateralization and protrusion.

For all the tests, a 5\% significance level was considered and the softwares used were BioEstat 5.0 and the GraphPad 6.0.

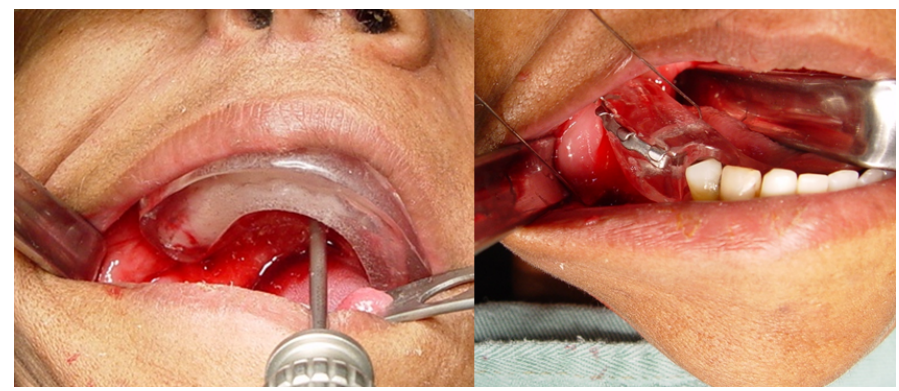

Figure 7. intra-operative adaptation of surgical guides for vertical dimension and oclusion maintenance

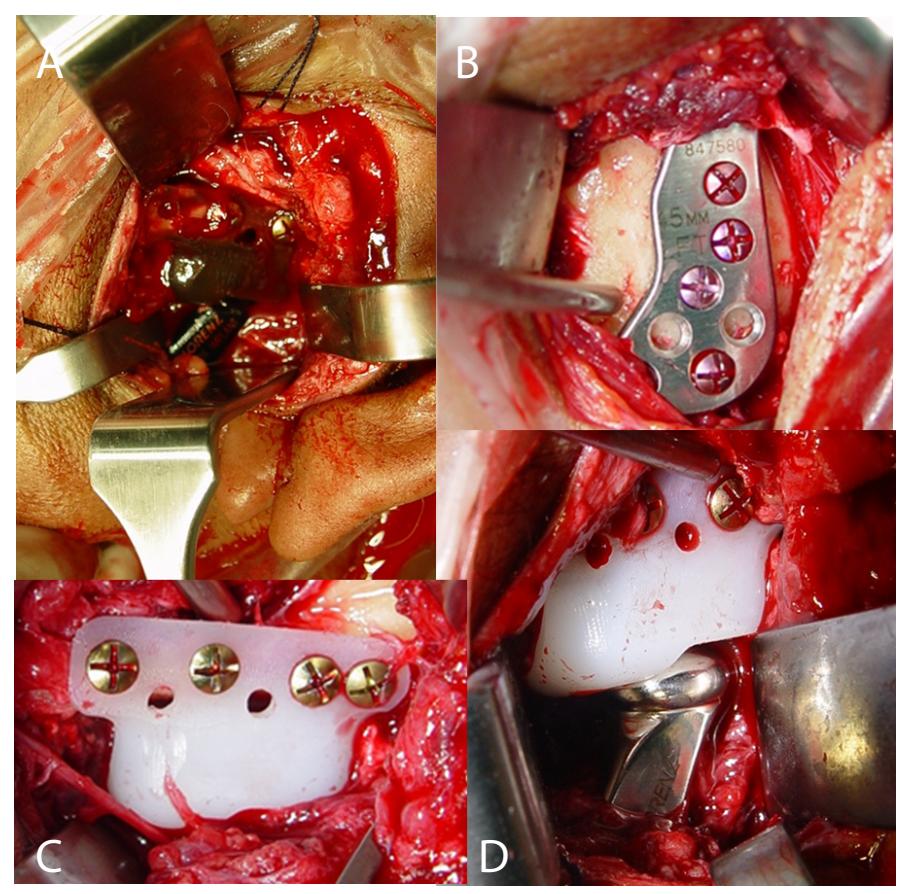

Figure 8. Installation of the articular prosthesis

A) Template of the fossa component, B) Installation of the definitive mandibular component C) Installation of the final component of the fossa D) Adapted prosthesis

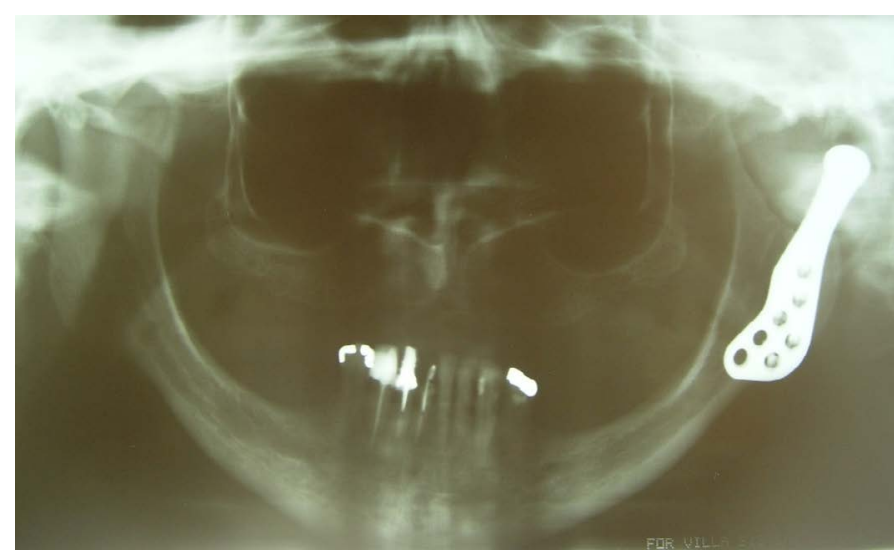

Figure 9. Post-Op X-ray showing proper adaptation of left articular prosthesis

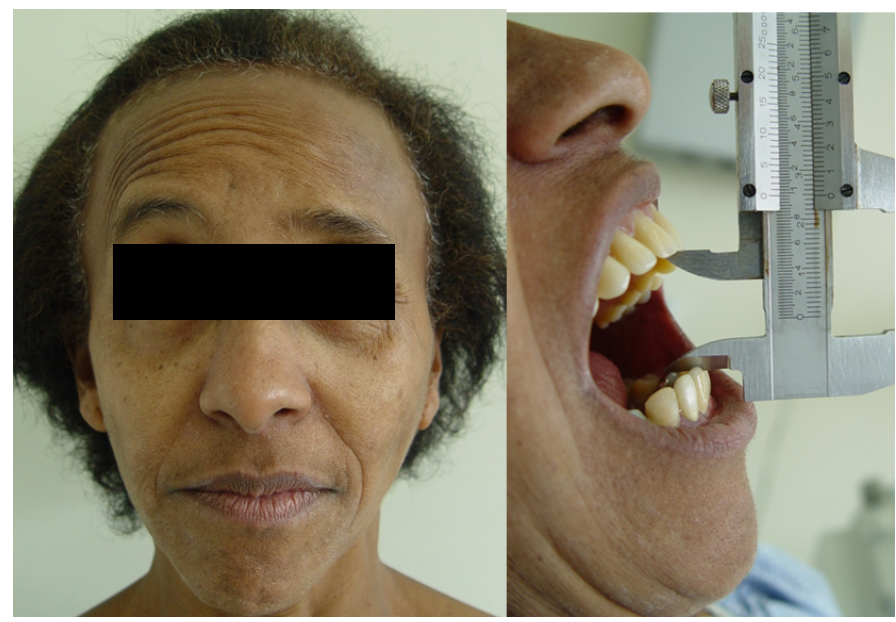

Figure 10. Post-Op follow-up showing oral opening improvement and preserved facial innervation.

\section{Results}

In this study 17 men were evaluated, with an average age of 37.2 \pm 1.9 years, in addition, 27 females with an average age of $40.9 \pm 2.1$ years. There was not significant statistic variation (Mann-Whitney, $\mathrm{p}=0.2014)$ among ages, genre-wise. The majority of the volunteers were white $(84.1 \%)$, whereas $13.6 \%$ were black and $2.3 \%$ were mixed-race.

The time of use of the prosthesis by the volunteers was, within the majority, up to 5 years (65.9\%). 27.3\% referred a time of use of 6 to 10 years, and $6.8 \%$ more than 10 years.

Table 1 and 2 exhibit, respectively, the personal background and previous surgeries they went through. Table 3 shows the relation between dental general condition of the volunteers and the etiology that leaded to the installation of the prosthesis. Table 4 shows the relation amongst the diagnoses obtained through radiographs (right and left TMJ transcranial x-ray, as well as orthopantomography) and/ or TMJ - CT of the 44 study subjects.

It was possible to corroborate that resorption/ deformation, as well as fibrosis/ankylosis/arthrosis were more prevalent (Chi Squared Test, $\mathrm{p}>0.05$ ) than the others, both by the CT and the X-Rays.

Graphics 1, 2 and 3 show, respectively, the measures (in $\mathrm{mm}$ ) of mouth opening, lateralization and protrusion, during the pre and post- op. 
Table 1. Subject distribution according to prior disease.

\begin{tabular}{|c|c|}
\hline Prior disease & Distribution \\
\hline Artrhitis & $3(6,8 \%)$ \\
\hline Diabetes & $1(2,3 \%)$ \\
\hline Colagen Disease & $1(2,3 \%)$ \\
\hline GSW & $1(2,3 \%)$ \\
\hline Osteopenic fibromyalgia & $1(2,3 \%)$ \\
\hline Hypertension & $4(9,1 \%)$ \\
\hline Hypertension/Diabetes & $1(2,3 \%)$ \\
\hline Hypothyroidism & $1(2,3 \%)$ \\
\hline Non & $31(70,5 \%)$ \\
\hline
\end{tabular}

Table 2. Distribution of the subjects regarding prior surgery

\begin{tabular}{|c|c|}
\hline Prior surgery & Distribution \\
\hline Tonsilectomy & $1(2.3 \%)$ \\
\hline Appendectomy & $2(4.5 \%)$ \\
\hline Arthroplasty & $1(2.3 \%)$ \\
\hline Bariatric surgery & $1(2.3 \%)$ \\
\hline Orthognathic surgery & $6(13.6 \%)$ \\
\hline Discopexy & $2(4.5 \%)$ \\
\hline Bilateral TMJ discopexy & $2(4.5 \%)$ \\
\hline Mandibular fracture fixation & $1(2.3 \%)$ \\
\hline Total Hysterectomy & $1(2.3 \%)$ \\
\hline Breast and uterus & $1(2.3 \%)$ \\
\hline Reduction and fixation of condylar fracture & $1(2.3 \%)$ \\
\hline Non & $25(56.8 \%)$ \\
\hline
\end{tabular}

Table 3. Relation between dental condition and prosthesis etiology.

\begin{tabular}{|c|c|c|c|c|c|}
\hline & \multicolumn{5}{|c|}{ Dental Condition } \\
\hline Etiology & Good & $\begin{array}{c}\text { Partially } \\
\text { edentulous }\end{array}$ & Overbite & Bad & Total \\
\hline Arthritis & $2(4,5 \%)$ & - & $1(2,3 \%)$ & - & $3(6,8 \%)$ \\
\hline GSW/accidents & $3(6,8 \%)$ & - & - & - & $3(6,8 \%)$ \\
\hline $\begin{array}{c}\text { Fibrosis/ankylosis/ } \\
\text { artrhosis }\end{array}$ & $19(43,2 \%)$ & $2(4,5 \%)$ & - & $1(2,3 \%)$ & $22(50 \%)$ \\
\hline Osteomyelitis & - & - & - & $1(2,3 \%)$ & $1(2,3 \%)$ \\
\hline $\begin{array}{c}\text { Reabsorption/ } \\
\text { deformation }\end{array}$ & $2(4,5 \%)$ & - & - & - & $2(4,5 \%)$ \\
\hline Non reported & - & $1(2,3 \%)$ & - & - & $1(2,3 \%)$ \\
\hline $\begin{array}{c}\text { Trauma/sequel/ } \\
\text { fracture }\end{array}$ & $12(27,3 \%)$ & - & - & - & $12(27,3 \%)$ \\
\hline Total & $38(86,4 \%)$ & $3(6,8 \%)$ & $1(2,3 \%)$ & $2(4,5 \%)$ & $44(100 \%)$ \\
\hline
\end{tabular}

It was possible to observe that mouth opening during the post-op was wider than the pre-op (Wilcoxon Test, $\mathrm{p}<0,0001$ ). During the preop, mouth opening was in average of $17 \pm 7.91$ ( \pm Standard Deviation), increasing to $31.5 \pm 3.41 \mathrm{~mm}$ in the post-op, exhibiting an average increase of $14.6 \pm 8.04$. It was noted that 38 of the subjects $(86,4 \%)$ showed mouth opening increase in the post-op, whereas 1 individual remained with the same opening, and another reduced $3 \mathrm{~mm}$ in the post-op.

Similarly, lateralization in the post-op $(3.1 \pm 1.71 \mathrm{~mm})$ was bigger (Wilcoxon test, $\mathrm{p}<0.05$. than the pre-op $(2.4 \pm 1.86$ ), although the average variation was $0.7 \pm 2.07 \mathrm{~mm}$. Lateralization increased in 23 subjects (52.3\%) however, remained the same in $13(29.5 \%)$ and reduced in $8(18.2 \%)$ of them. In 3 subjects, the reduction was in the order of $3 \mathrm{~mm}$. The increase, when present, was also significant, for in $16(36.4 \%)$ volunteers was in the order of $2-3 \mathrm{~mm}$.

Protrusion also increased significantly (Wilcoxon Test, $\mathrm{p}<0.05$ ), as observed in Graphic 3. During the pre-op, the protrusion average ( \pm Standard Deviation) was of $2.3 \pm 1.8 \mathrm{~mm}$, increasing to $2.8 \pm 1.65 \mathrm{~mm}$ in the post-op (average increase of $0.5 \pm 1.56 \mathrm{~mm}$ ) (Figure 11).
In $21(47.7 \%)$ subjects, average protrusion was noted to be wider. In 12 subjects $(27.3 \%)$ protrusion remained the same, and in 11 of them $(25 \%)$ decrease was observed. Although the average protrusion increase or decrease was found to be between 1 and $3 \mathrm{~mm}, 1$ subject lost $5 \mathrm{~mm}$ in the pot-op.

Table 5 shows, in general, the symptoms of the subject before and after surgery. It is possible to observe there were differences between the periods.

The clicking reports, crepitation, cephalea, facial asymmetry and especially local pain decreased significantly (Fisher's Exact Test, $p$ $<0.05)$ after surgery. However, edema, which was small preoperatively did not show statistically significant differences (Fisher's Exact Test, p> 0.05 ) between the periods, and the same was noted in mouth opening deviation and limitation.

It was observed that all cases of crepitation, edema, clicking, facial asymmetry and pain experienced complete remission after surgery except for 1 case of clicking and a 1 of facial asymmetry.

All subjects answered yes to the first two questions ("1 - Were you really determined to go through this surgery?" And "2 - Did you understand why you needed the surgery?") of the questionnaire. No accidents or complications during the surgery were reported.

Table 6 shows the relationship between questions 3 ("Did your mastication improve after surgery?") And 4 (“ Did your social life improve after surgery?") of the questionnaire.

Table 4. Distribution of signs and symptoms regarding pre and post-op periods.

\begin{tabular}{|c|c|c|c|c|}
\hline $\begin{array}{l}\text { Signs and } \\
\text { symptoms }\end{array}$ & Side & Pre-Op & Post-Op & $\mathrm{p}^{*}$ \\
\hline \multirow{4}{*}{ Click } & Both sides & $8(18,2 \%)$ & $1(2,3 \%)$ & \multirow{4}{*}{0,0016} \\
\hline & Right & $2(4,5 \%)$ & - & \\
\hline & Left & $2(4,5 \%)$ & - & \\
\hline & Neither & $32(72,7 \%)$ & $43(97,7 \%)$ & \\
\hline \multirow{4}{*}{ Crepitation } & Both sides & $16(36,4 \%)$ & - & \multirow{4}{*}{0,0001} \\
\hline & Right & $1(2,3 \%)$ & - & \\
\hline & Left & $3(6,8 \%)$ & - & \\
\hline & Neither & $24(54,5 \%)$ & $44(100 \%)$ & \\
\hline \multirow{2}{*}{ Edema } & Both & $2(4,5 \%)$ & - & \multirow{2}{*}{0,4943} \\
\hline & Neither & $42(95,5 \%)$ & $44(100 \%)$ & \\
\hline \multirow{2}{*}{$\begin{array}{l}\text { Movement } \\
\text { limitation }\end{array}$} & Yes & $41(93,2 \%)$ & $39(88,6 \%)^{* *}$ & \multirow{2}{*}{0,7133} \\
\hline & Non & $3(6,8 \%)$ & $5(11,4 \%)$ & \\
\hline \multirow{2}{*}{$\begin{array}{c}\text { Facial } \\
\text { asymmetry }\end{array}$} & No & $31(70,5 \%)$ & $43(97,7 \%)$ & \multirow{2}{*}{0,0007} \\
\hline & Yes & $13(29,5 \%)$ & $1(2,3 \%)$ & \\
\hline \multirow{3}{*}{$\begin{array}{l}\text { Opening oral } \\
\text { deviation }\end{array}$} & Right & $5(11,4 \%)$ & $2(4,5 \%)$ & \multirow{3}{*}{0,1178} \\
\hline & Left & $4(9,1 \%)$ & $1(2,3 \%)$ & \\
\hline & Non & $35(79,5 \%)$ & $41(93,2 \%)$ & \\
\hline \multirow{4}{*}{ Cephalea } & Both sides & $38(86,4 \%)$ & $23(52,3 \%)$ & \multirow{4}{*}{0,0004} \\
\hline & Right & - & $1(2,3 \%)$ & \\
\hline & Left & $1(2,3 \%)$ & - & \\
\hline & Neither & $5(11,4 \%)$ & $20(45,5 \%)$ & \\
\hline \multirow{2}{*}{$\begin{array}{l}\text { Chewing } \\
\text { difficulty }\end{array}$} & Both sides & $39(88,6 \%)$ & $33(75 \%)$ & \multirow{2}{*}{0,1658} \\
\hline & Neither & $5(11,4 \%)$ & $11(25 \%)$ & \\
\hline \multirow{4}{*}{ Local pain } & Both sides & $30(68,2 \%)$ & - & \multirow{4}{*}{0,0001} \\
\hline & Right & $1(2,3 \%)$ & - & \\
\hline & Left & $2(4,5 \%)$ & - & \\
\hline & Neither & $11(25 \%)$ & $44(100 \%)$ & \\
\hline
\end{tabular}

* - Fisher's exact test considering presence or absence of sign / symptom.

** - Limitation of the postoperative movement: 29 (65.9\%) small and bilateral; $6(13.6 \%)$ bilateral; $2(4.5 \%)$ only on the left side; $1(2.3 \%)$ only on the right side and $1(2.3 \%)$ small on the right side. 


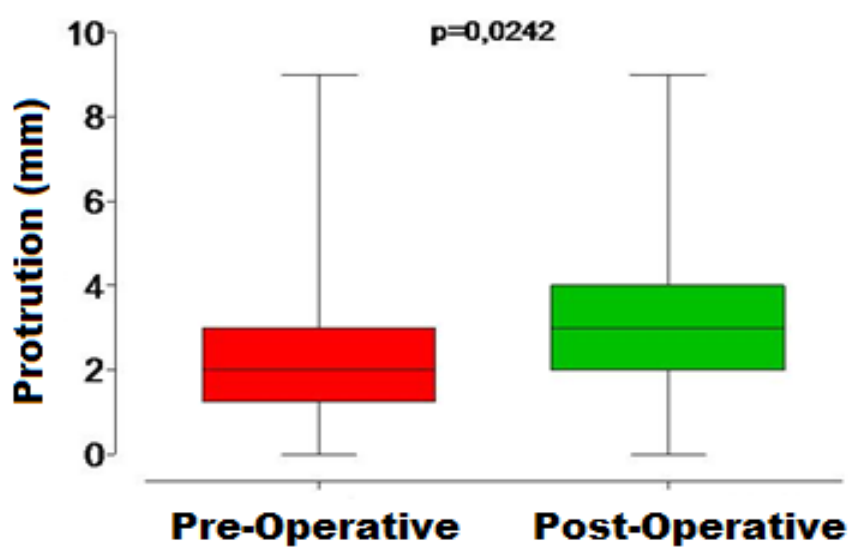

Figure 11. Graph 3 - Measurement of protrusion in the pre and postoperative periods. The center line represents the median, the box represents the 1st and 3rd quartiles and the Swiss represent the maximum and minimum values

It was observed that 33 (75\%) subjects had improvement in both mastication and social life, whereas 37 (84.1\%) showed improvement in mastication only, and 40 (90.9\%) showed improvement in social life only.

When asked about the discomfort after surgery, $8(18.2 \%)$ answered "great discomfort", 10 (22.7\%) answered "moderate discomfort" and 26 (59.1\%) answered "mild discomfort." Table 7 shows the relationship between these answers and questions 3 and 4 .

As can be seen in Table 7, there was no relationship between the answers to questions 3 and 4 and post-operative discomfort. Similarly, there was no relationship (Chi-Square, $\mathrm{p}>0.05$ ) between postoperative discomfort and intraoperative aspects of surgery. No relationship with the prosthesis installed was found either, as shown in Tables 8 .

Graph 4 shows the relationship between post-surgical discomfort with differences (in $\mathrm{mm}$ ) between the pre- and postoperative mouth opening, lateralization and protrusion (Figure 12).

In the data analysis (Kruskal-Wallis test) there were no statistically significant differences between the postoperative discomfort levels considering the opening $(p=0.3914)$, lateralization $(p=0.6256)$ and protrusion $(\mathrm{p}=0.9468)$. Furthermore, it was observed that the differences between the initial and final mouth opening were increased between 10 and $20 \mathrm{~mm}$, regardless of the level of postoperative discomfort. As for the laterality this difference was between 0 and 2 $\mathrm{mm}$, and for the protrusion the difference went from $1 \mathrm{~mm}$ reduction to $2 \mathrm{~mm}$ increasing.

\section{Discussion}

The results of this study point to a greater frequency of female 1.6: 1 of the 44 participants with no difference between the ages in terms of gender (40.9 Years on Average), above the age limit proposed by 6 that contraindicate TMJ prostheses in growing children and patients. The prevalence in females and the average age corresponded to that found in the literature on total replacement of TMJs by joint prostheses $[7,8]$. Joint diseases are more common in females. Some authors cite a proportion of 3: 1, although some studies proportions vary between 15.5: 19 and 22: 1 10, and when in aged 20-40 [11-13]. These data may be correlated with the common hormonal change in women in this range age, justifying the high number of females with changes in TMJs [7].

The time of use of the prostheses by the volunteers was mostly 5 years $(65.9 \%)$, and $27.3 \%$ reported from 6 to 10 years of use and $6.8 \%$ more than 10 years. In our study it was observed that the time of use of the prosthesis was 18 months to 15 years. One of the major points of questioning is about the longevity of these prostheses. Experienced authors expectation is 20 years of time use [14]. Relationship between time use of the prosthesis and laterality (Unilateral Or Bilateral) was not found, but it can be observed that all patients evaluated and undergoing treatment are in full use and without reinterventions needed for postoperative complications. There is concern about the contralateral joint stability, periodontal changes and anatomical and functional restrictions in cases of unilateral prosthesis [15], but complications were not observed, to these days, in the patients who underwent this particular procedure (15-34.1\%).

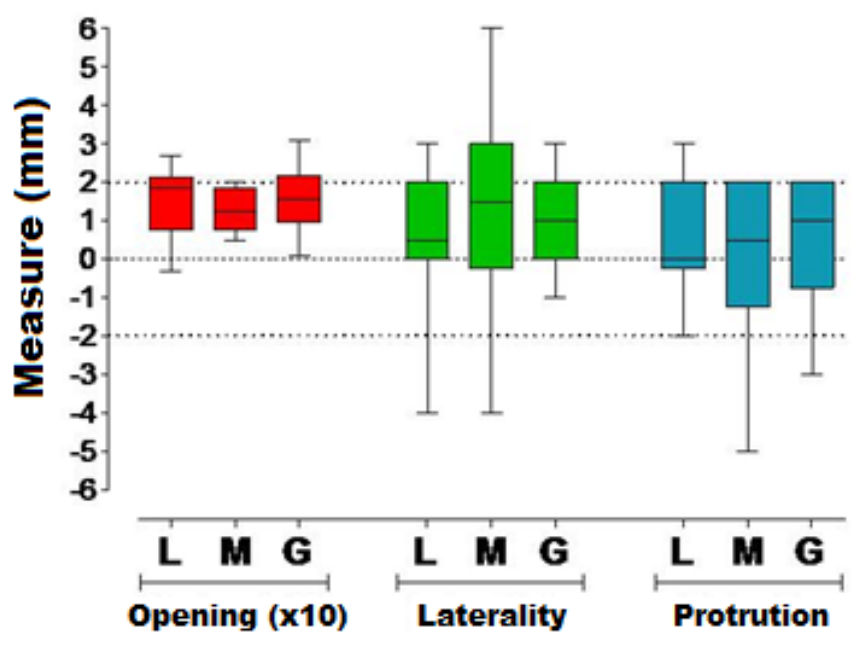

Figure 12. Graph 4 - Relationship between post-surgical discomfort $(\mathrm{L}=$ mild, $\mathrm{M}=$ moderate and $\mathrm{G}=$ large) with differences (pre and postoperative) of the buccal opening ( $\mathrm{x}$ $10)$, laterality and protrusion. The center line represents the median, the box represents the 1 st and 3rd quartiles and the Swiss represent the maximum and minimum values.

Table 5. Distribution of relation between questions 3 and 4 .

\begin{tabular}{|c|c|c|c|c|}
\hline & \multicolumn{3}{|c|}{ Did your social life improve after surgery? } \\
\hline $\begin{array}{c}\text { Did your chewing improve } \\
\text { after surgery? }\end{array}$ & $\begin{array}{c}\text { It improved } \\
\text { but not } \\
\text { the way I } \\
\text { expected }\end{array}$ & It improved & $\begin{array}{c}\text { It improved } \\
\text { a lot }\end{array}$ & General total \\
\hline $\begin{array}{c}\text { It improved but not the way } \\
\text { I expected }\end{array}$ & - & $1(2,3 \%)$ & $3(6,8 \%)$ & $4(9,1 \%)$ \\
\hline It improved & $3(6,8 \%)$ & $6(13,6 \%)$ & $3(6,8 \%)$ & $12(27,3 \%)$ \\
\hline It improved a lot & $4(9,1 \%)$ & $9(20,5 \%)$ & $15(34,1 \%)$ & $28(63,6 \%)$ \\
\hline General total & $7(15,9 \%)$ & $16(36,4 \%)$ & $21(47,7 \%)$ & $44(100 \%)$ \\
\hline
\end{tabular}

Table 6. Discomfort profile, on the basis of the answers to questions 3 and 4

\begin{tabular}{|c|c|c|c|c|c|}
\hline & & \multicolumn{3}{|c|}{ Discomfort after surgery } & \multirow[b]{2}{*}{ General Total } \\
\hline & & Mild & Moderate & Big & \\
\hline & $\begin{array}{c}\text { Total } \\
\text { discomfort }\end{array}$ & $26(59,1 \%)$ & $10(22,7 \%)$ & $8(18,2 \%)$ & $44(100 \%)$ \\
\hline \multirow{3}{*}{$\begin{array}{c}\text { Did your } \\
\text { chewing } \\
\text { improve after } \\
\text { surgery? }\end{array}$} & $\begin{array}{c}\text { It improved } \\
\text { but not how I } \\
\text { expected }\end{array}$ & $6(13,6 \%)$ & $1(2,3 \%)$ & - & $7(15,9 \%)$ \\
\hline & It improved & $7(15,9 \%)$ & $6(13,6 \%)$ & $3(6,8 \%)$ & $16(36,4 \%)$ \\
\hline & $\begin{array}{c}\text { It improved } \\
\text { a lot }\end{array}$ & $13(29,5 \%)$ & $3(6,8 \%)$ & $5(11,4 \%)$ & $21(47,7 \%)$ \\
\hline \multirow{3}{*}{$\begin{array}{c}\text { Did your } \\
\text { social life } \\
\text { improve after } \\
\text { surgery? }\end{array}$} & $\begin{array}{c}\text { It improved } \\
\text { but not how I } \\
\text { expected }\end{array}$ & $1(2,3 \%)$ & $2(4,5 \%)$ & $1(2,3 \%)$ & $4(9,1 \%)$ \\
\hline & It improved & $12(27,3 \%)$ & - & - & $12(27,3 \%)$ \\
\hline & $\begin{array}{l}\text { It improved } \\
\text { a lot }\end{array}$ & $13(29,5 \%)$ & $8(18,2 \%)$ & $7(15,9 \%)$ & $28(63,6 \%)$ \\
\hline
\end{tabular}


Table 7. Distribution of the relation between post-Op discomfort and operative aspect of the TMJ's.

\begin{tabular}{|c|c|c|c|c|}
\hline & \multicolumn{3}{|c|}{ Discomfort after surgery } & \multicolumn{1}{|c|}{} \\
\hline Operative aspect & Mild & Moderate & Big & General Total \\
\hline Fybrosis/ankilosys/arthrosis & $13(29,5 \%)$ & $5(11,4 \%)$ & $3(6,8 \%)$ & $21(47,7 \%)$ \\
\hline Reabsorption/deformation & $5(11,4 \%)$ & $4(9,1 \%)$ & $4(9,1 \%)$ & $13(29,5 \%)$ \\
\hline Presence of articular disc remnants & $3(6,8 \%)$ & - & - & $3(6,8 \%)$ \\
\hline Posterior vertical dimention loss & $2(4,5 \%)$ & - & $1(2,3 \%)$ & $3(6,8 \%)$ \\
\hline Fracture & $1(2,3 \%)$ & - & - & $1(2,3 \%)$ \\
\hline No condyle & $1(2,3 \%)$ & - & - & $1(2,3 \%)$ \\
\hline Non reported & $1(2,3 \%)$ & $1(2,3 \%)$ & - & $2(4,5 \%)$ \\
\hline General Total & $26(59,1 \%)$ & $10(22,7 \%)$ & $8(18,2 \%)$ & $44(100 \%)$ \\
\hline
\end{tabular}

Table 8. Distribution of the relation between post-Op discomfort and the used prosthesis.

\begin{tabular}{|c|c|c|c|c|}
\hline & \multicolumn{3}{|c|}{ Discomfort after surgery } & \multicolumn{1}{|c|}{} \\
\hline & Mild & Moderate & Big & General Total \\
\hline Bilateral prosthesis & $17(38,6 \%)$ & $5(11,4 \%)$ & $7(15,9 \%)$ & $29(65,9 \%)$ \\
\hline Unilateral right prosthesis & $6(13,6 \%)$ & $2(4,5 \%)$ & - & $8(18,2 \%)$ \\
\hline Unilateral left prosthesis & $3(6,8 \%)$ & $3(6,8 \%)$ & $1(2,3 \%)$ & $7(15,9 \%)$ \\
\hline General Total & $26(59,1 \%)$ & $10(22,7 \%)$ & $8(18,2 \%)$ & $44(100 \%)$ \\
\hline
\end{tabular}

As conclusion, total TMJs replacement with prostheses have good results with improved function and decreased pain with few complications according with the literature [8] and [16-19]. And the database will grow as surgeons adhere to their routine, the TMJ reconstruction with use of aloplastic prostheses and the prostheses are prospectively followed for at least 10 years [1].

Regarding the presence of systemic disease in this study they were present in only 13 (29.5\%) patients. The most common diseases were hypertension and arthritis, being related to the major diseases that cause joint disorders, which are inflammatory or local resorptive pathologies, autoimmune diseases $[4,12,14,20]$, in addition to fibrous or bony ankylosis which are among the main indications for TMJ prostheses [3].

Most patients in this study (25 to $56.8 \%$ ) had not undergone previous surgery, and among those who underwent, 06 (13.6\%) of them were to orthognathic surgery, 04 (9\%) to discopexia, being bilateral in 02 patients, $01(2.3 \%)$ mandible fracture fixation surgery and $01(2.3 \%)$ arthroplasty, according to the study by Souza (2009) [15]. In the other patients immediate reconstruction was performed with TMJ prosthesis, divergent from the literature which suggests that patients who are candidate for condylar prosthesis installation surgery are those with multiple previous interventions in the region $[13,14,20]$, these being the ones who have the worst results and lower rate of success $[13,14]$.

It still exists some discussion about the type of prosthesis that has a better indication for the patient, many authors argue that the custom prostheses are advantageous in planning, and adaptation, besides the possibility of giving the facial contour, the angle and mandibular arch, especially in patients who have large defects $[19,21]$. However, for patients without previous interventions and normal anatomy, "stock" prosthesis is a good alternative, eliminating costs and elaboration time ${ }^{22}$, according to our study in which most of the patients (25 to $56.8 \%$ ) had not undergone previous surgery and obtained excellent results with the Biomet stock prosthesis [1,8,15,17,23-25] .

In this study the majority of the patients had good dental condition and independently (good or otherwise) the most frequent etiology was resorption/deformation which represented $47.7 \%$ (21) of the total, followed by fibrosis/ankylosis/arthrosis representing $29.5 \%$ (13) observed through X-rays and/or CT scan. In studies by Briceño et al.
(2013) [26] with customized aloplastic unilateral replacements (48.1\%) or bilateral replacements $(52.19 \%)$ the most frequent etiologies were mutilation of TMJ by gunshot wounds or previous surgery (22\%) followed by ankylosis (18.5). Another study [1] highlights that the main causes were osteoarthritis, failures in previous operations, ankylosis and arthritis. The etiological factors of these conditions are many and may be related to congenital or acquired changes, or both local and systemic factors $[2,8,11]$. In this study there was an increase of the amplitude of mandibular movements, and mouth opening postoperatively $(31.5 \pm 3,41 \mathrm{~mm})$ was higher than preoperatively (17 \pm $7,91 \mathrm{~mm})$ in $38(86.4 \%)$ individuals. This agrees with the literature, as the results of studies on the functional improvement and interincisal opening are promising $[11,13,27]$.

One of the reasons for the higher number of patients with increase in protrusion measures and laterality is in fact the new condylar prosthesis having the rotation point condyle inferiorly to the center of the natural condyle, improving mandibular function, which could explain the significant improvement in the patients evaluated in this study $[15,28]$.

It is noted that for laterality and protrusion, a bigger number of patients with a reduction of these movements was obtained, which is a common fact in postoperative condylar prosthesis installation, and that is related to the detachment of the lateral pterygoid muscles responsible for this function [2,24]. Despite involvement of pterygoid and masseter (which are disinserted) during the placement of the prosthesis, this does not interfere with its functionality, clinical and functional improvement after installing the prosthesis are obtained as well as result predictability [29]. It is important to note that installing one or both sides of the prosthesis was not correlated with the amplitude of mandibular movements.

In our study all patients underwent an extensive program of postoperative physical therapy, taking into account that aggressive postoperative physical therapy must be followed, as studies have shown that whatever surgical technique in the TMJ reconstruction procedure, the results are better sustained [30,32].

The main objectives of the TMJ reconstruction are to improve the function and mandibular shape, reduce or eliminate pain and prevent future morbidities $[12,13,27]$. The improvement of the patients, both in the objective aspect and the subjective was quite significant in this study, in agreement with the data presented in the literature $[9,11,12]$, given that in this study there was remission in all cases of edema, pain, cephalea, facial asymmetry and clicking, corroborating satisfactory cosmetic and functional results presented in the literature $[8,18,22,33]$.

The evaluated factors are interconnected, that is, the improvement in mouth opening is related to minor pain in the TMJ region, and consequently to masticatory functions and diet of the patient improvement. It is important to note that most of our patients (26 to $59.1 \%$ ) reported mild discomfort during the postoperative period, and only 08 (18.2\%) patients reported major postoperative discomfort, which showed no correlation with intraoperative aspects, uni- or bilateral replacement, functional satisfaction and social life. It was observed that $33(75 \%)$ patients had improvement in both mastication and social life; 37 (84.1\%) showed improvement in mastication and 40 (90.9\%) showed improvement in social life. As prospective studies by Linsen et al. (2013) 34 which assessed the bite force in patients receiving TMJ prosthesis. They also stated that the biomechanical integrity of the stomatognathic system and grinding food capacity can be increased by alloplastic replacement of TMJs. 
Another plus was that in this study, no trans-surgical injury or postoperative complications took place. Some authors refer in their studies that the most common complications are neuropraxis mainly caused by retraction maneuvers and use of electrocautery, and intraoperative bleeding due to injury of maxillary artery branches and plexus pterigoideo ${ }^{4}$ in addition to infections, malocclusion, hematoma, metallic component dislocations, prosthesis attachment loss, and even locoregional bone formation are likely to happen $[4,15]$, suggesting this procedure requires some experience of the surgical team; however, when the procedure is performed with well-employed surgical technique, along with adequate postoperative follow-up, clinical success is expected as with our study. In this study postoperative comfort was not directly related to the intraoperative aspect of the TMJ, to the number of prosthesis used, to the masticatory satisfaction level after surgery, to the improvement in social life or to the differences between the pre- and postoperative for any of the measures studied as well as the studies $[1,8,15,17,34]$.

Many types of condylar prostheses were tested over the years since the pioneers prototypes such as Risdon's in 1933, to the most currently used, which are prefabricated condylar prosthesis (BIOMET/ Lorenz, TMJ implants) and prostheses customized using CAD/CAM technology (TMJ Concepts) and the indication of TMJ prosthesis was based on the surgeon's experience as described [2,20,35]. Recent studies demonstrate that alloplastic devices have advantages when compared to autografts for the rehabilitation of patients, especially when considering the need of donor sites, morbidity and surgical time, and longer lasting results $[1,4,8,17,21,25]$.

A fatty tissue interposition technique between the prosthetic components is described to avoid complications such as ectopic bone formation and improve jaw function in addition to reducing the need for reinterventions[12], with the justification that is the tissue that suffers fewer metaplasia, besides promoting an environment that favors the mandibular movement, but this technique has not been used in prostheses in this study, because the provision of $\mathrm{W}$. Lorens prosthesis when properly installed has angles that make dislocations difficult, and has thickness that hinder exaggerated bone formation and local reankylosis [15,19].

Regarding the alloplastic material for reconstruction of the temporomandibular joint, although there is a significant number of articles published in prestigious journals, works more scientific status, as is the case of a systematic review or meta-analysis have not been found. What stood out was the predominance of clinical studies on the use of TMJ Concepts and W Lorenz types, some performed in very expressive numerical samples of individuals, others in smaller groups, in which the selection of cases was not homogeneous, there is no discrimination in relation to age, gender, ethnicity, dental or occlusal conditions, presence of parafunction and pathology nature to be treated, it is noted that the findings are very similar: postoperative life quality improvement as to mouth opening, through the measurement of interincisal distance; remission of painful symptoms associated with pre-existing conditions; and improvement in masticatory and phonetic function, and that the success of this procedure has a strong link with the number of previous surgeries and adherence to a postoperative physical therapy program [8].

Regarding the biocompatibility of materials for the reconstruction of the TMJ, both TMJ Concepts and the W. Lorenz, there is consensus that they conform to the gold standards of medical orthopedics, which preconize the articulation of a component made of ultra- high molecular weight polyethylene material against chromium-cobaltmolybdenum $[8,18]$.

With the results obtained in this study, it was observed that there was an improvement both masticatory and social-life-wise of patients who underwent joint replacement for prefabricated condyle BIOMET/W.Lorens prosthesis procedure, without any intraoperative accidents report or postoperative complications associated with mild discomfort during the postoperative period referred to by most patients . Promising results that provide security as well as a safe and effective procedure for patients with temporomandibular joint reconstruction indication 8.36

It can be concluded that patients treated with total reconstruction of the temporomandibular joint have significant clinical improvement in masticatory function, mouth opening, the remission of painful symptoms and the degree of patient satisfaction postoperatively.

\section{References}

1. 1 Idle MR, Lowe D, Rogers SN, Sidebottom AJ, Speculand B, Worral SF (2014) UK temporomandibular joint replacement database: report on baseline data. Br J Oral and Maxillofac Surg 52: 203-207. [Crossref]

2. Quinn P (2000) Alloplastic reconstruction of the temporomandibular joint. In: Fonseca $\mathrm{RJ}$ (Edr). Oral and maxillofacial surgery: Temporomandibular disorders. Philadelphia. WB Saunders Company 316-332.[Crossref]

3. CapoteA, Rodriguez-Campo FJ, Escorial V, Munoz-Guerra M (2006) Total tempomandibular joint reconstructionwithalloplasticprothesis. Review our experience. J CranioMaxillofac Surg 34.

4. Machon V, Hirjak D, Beno M, Foltan R (2012) Total aloplastic temporomandibular jointreplacement: the czech-slovak initial experience. Int. J. Oral maxillofac Surg 41 : 514-517. [Crossref]

5. 5 Meade EA, Inglehart MR (2010) Young patients' treatment motivation and satisfaction with orthognathic surgery outcomes: the role of "possible selves". Am J Orthod Dentofacial Orthop 137: 26-34. [Crossref]

6. Mercuri LG (2000) Use of alloplastic protheses for TMJ reconstruction. JOral Maxillofac Surg 58:70-75. [Crossref]

7. Wolford LM, Mercuri LG, Schneiderman ED, Movahed R, Allen W (2015) TwentyYear Follow-up Study on aPatient-Fitted Temporomandibular JointProsthesis: The Techmedica/TMJConcepts Device. J Oral Maxillofac Surg 73: 952-960. [Crossref]

8. Aagaard E, Thygesen T (2014) A prospective, single-centre study on patient outcomes following temporomandibular joint replacement using a custom-made Biomet TM. prosthesis. Int J Oral Maxillofac. Surg. 43: 1229-1235. [Crossref]

9. Burgess M, Bowler M, Otago NZ, Jones R, Hase M, et al. (2014) Improved Outcomes After Alloplastic TMJ Replacement: Analysis of a Multicenter Study From Australia and New Zealand. J Oral Maxillofac Surg 72: 1251-1257. [Crossref]

10. Torres-Chávez KE, Fischer L, Teixeira JM, Fávaro-Moreira NC, Obando-Pereda GA, et al.( 2011) Sexual dimorphism on cytokines expression in the temporomandibular joint: the role of gonadal steroid hormones. Inflammation 34: 487-498. [Crossref]

11. Leandro LF, Ono HY, Loureiro CC, Marinho K, Guevara HA (2013) A ten-year experience and follow-up of three hundred patients fitted with the Biomet/Lorenz Microfixation TMJ replacement system. Int J Oral Maxillofac Surg 42:1007-1013. [Crossref]

12. Mercuri LG, Wolford LM, Sanders B, White RD, Hurder A, et al. (1995) Custom CAD/ CAM total temporomandibular joint reconstruction system: preliminary multicenter report. J Oral Maxillofac Surg 53: 106-115. [Crossref]

13. Wolford LM, Dingwerth DJ, Talwar RM, Pitta MC (2003) Comparison of 2 temporomandibular joint total joint prothesis systems. J Oral Maxillofac Surg 62: 685690. [Crossref]

14. Guarda-Nardini L, Manfredini D, Ferronato G (2008) Temporomandibular joint total replacement prosthesis: current knowledge and considerations for the future. Int J Oral Maxillofac Surg 37: 103-110. [Crossref]

15. Wolford LM, Morales-Ryan CA, García-Morales P, Perez D (2009) Surgical management of mandibular condylar hyperplasia type 1. Proc (Bayl Univ Med Cent) 22: 321-329. [Crossref] 
16. Loveless TP, Bjornland T, Dodson TB, Keith DA (2010) Efficacy of temporomandibularjoint ankylosis surgical treatment. J Oral Maxillofac Surg 68: 12761282. [Crossref]

17. Wolford LM, Rodrigues DB, McPhillips A (2010) Management of the infected temporomandibular joint total joint prosthesis. J Oral Maxillofac Surg. 68: 2810-2823. [Crossref]

18. Souza DP (2009) Avaliação clinic-funcional de pacientes submentidos a tratamento com prótese total de ATM. [dissertação] São Paulo: Faculdade de Odontologia da Universidade de São Paulo

19. Sidebottom AJ, Gruber E (2013) One-year prospective outcome analysis and complications following total replacement of the temporomandibular joint with the TMJ concepts system. Br J Oral and Maxillofac Surg 51: 620-624. [Crossref]

20. Mustafa el M, Sidebottom A (2014) Risk factors for intraoperative dislocation of the total temporomandibular joint replacement and its management. Br J Oral Maxillofac Surg 52:190-192. [Crossref]

21. Murdoch B, Buchanan J, Cliff J (2013) Temporomandibular joint replacement: a New Zealand perspective. Int J Oral Maxillofac Surg 43: 595-599. [Crossref]

22. Saeed N, Hensher R, McLeod N, Kent J (2002) Reconstruction of the temporomandibularjoint autogenous compared with alloplastic. Br J Oral Maxillofac Surg 40: 296-299. [Crossref]

23. EA Al-Moraissi, TM El-Sharkawy, RM Mounair, TI El-Ghareeb (2015) A systematic review and meta-analysis of the clinical outcomes for various surgical modalities in the management of temporomandibular joint ankylosis. Int J Oral Maxillofac. Surg 44: 470-482. [Crossref]

24. ShanYong Z, Liu H, Yang C, Zhang X, Abdelrehem A, et al. (2015) Modified surgical techniques for total alloplastic temporomandibular joint replacement: One institution's experience. J Craniomaxillofac Surg 43: 934-939. [Crossref]

25. Westermark A, Hedén P, Aagaard E, Cornelius CP (2011) The use of TMJ Concepts prostheses to reconstruct patients with major temporomandibular joint and mandibular defects. Int J Oral Maxillofac Surg 40: 487-496. [Crossref]

26. Abramowícz S, Barbick M, Rose SP, Dolwlck MF (2012) Adaptability of stock TMJ prosthesis to joints that were previously treated with custom joint prosthesis. Int J Oral MaxilloFac. Surg. 41: 518-520. [Crossref]

27. Giannakopoulos H, Sinn DP, Quinn P (2012) Biomet microfixation temporomandibular joint replacement system: a 3-year follow-upstudy of patients treated during 19952005. J Oral Maxillofac Surg 70: 787-794. [Crossref]
28. Leiggener CS, Erni S, Gallo LM (2012) Novel approach to the study of jaw kinematics in alloplastic TMJ reconstruction. Int. J. Oral MaxilloFac Surg. 41: 1041-1045. [Crossref]

29. Linsen SS, Reich RH, Teschke M (2013) Maximum voluntary bite force in patients with alloplastic total TMJ replacement--a prospective study. J Craniomaxillofac Surg 41: 423-428. [Crossref]

30. Briceño F, Ayala R, Delgado K, Piñango S (2013 ) Evaluation of temporomandibular joint total replacement with alloplastic prosthesis: observational study of 27 patients. Craniomaxillofac Trauma Reconstr 6:171-178 [Crossref]

31. WestermarkA (2010) Total reconstruction of thetemporomandibular joint. Up to8 years of follow-up of patientstreated with Biomet1 total jointprostheses. Int J Oral Maxillofac. Surg 39: 951-955.

32. Dimitroulis G (2014) Comparison of the outcomes of three surgical treatments for end-stage temporomandibular joint disease. Int J Oral Maxillofac Surg 43: 980-989. [Crossref]

33. Guven O (2004) Treatment of temporomandibular joint ankylosis by modified fossa prosthesis. J Craniomaxillofac Surg. 32: 236-242. [Crossref]

34. Felstead AM, Revington PJ (2011) Surgical managementof temporomandibular join ankylosisin ankylosing spondylitis.Int J Rheumatol. [Crossref]

35. 35. Egemen O, Ozkaya O, Filinte GT, Uscetin I, Akan M (2012) Two-stage total prosthetic reconstruction of temporomandibular joint in severe and recurrent ankylosis. J Craniofac Surg 23: 520-524. [Crossref]

36. Haq J, Patel N, Weimer K, Matthews NS (2014) Single stage treatment of ankylosis of the temporomandibular joint using patient-specific total joint replacement and virtual surgical planning. Br J Oral Maxillofac Surg 52: 350-355. [Crossref]

37. Chung DH, Hatch JP, Dolce C, Van Sickels JE, Bays RA, et al. (2001) Positionalchange of the hyoid bone afterbilateral sagittal split osteotomy with rigid and wire fixation. $A m$ J Orthod Dentofacial Orthop 119: 382-389 [Crossref]

38. Linsen SS, Reich RH, Teschke M (2013) Maximum voluntary bite force in patients with alloplastic total TMJ replacement--a prospective study. J Craniomaxillofac Surg 41: 423-428. [Crossref]

39. Wolford LM, Pitta MC, Reichel-Fischel O, Franco PF (2003) TMJ concepts/Techmedica custom made TMJ total prothesis: 5-year follow-up study. Int J Oral Maxillofac Surg 32: $268-274$.

Copyright: (C2017 Fernandes TCA. This is an open-access article distributed under the terms of the Creative Commons Attribution License, which permits unrestricted use, distribution, and reproduction in any medium, provided the original author and source are credited. 